\title{
THE SYNDROME OF ALTERNATING BRADYCARDIA AND TACHYCARDIA
}

\author{
BY \\ D. S. SHORT \\ From the National Heart Hospita. \\ Received September 15, 1953
}

Among the large number of patients suffering from syncopal attacks who attended the National Heart Hospital during a four-year period, there were four in whom examination revealed sinus bradycardia alternating with prolonged phases of auricular tachycardia. These patients presented a difficult problem in treatment. Each required at least one admission to hospital and in one case the symptoms were so intractable as to necessitate six admissions in five years.

Two patients had mitral valve disease, one of them with left bundle branch block. One had aortic valve sclerosis while the fourth had no evidence of heart disease.

\section{The Heart Rate}

The sinus rate usually lay between 30 and 50 a minute, a rate as slow as 22 a minute being observed in one patient (Table I). Sinus arrhythmia was noted in all four patients, wandering of

TABLE I

Rate in Sinus Rhythm and in Auricular Tachycardia

\begin{tabular}{|c|c|c|c|c|c|c|}
\hline \multirow[t]{2}{*}{ Case } & \multirow[t]{2}{*}{ Age } & \multirow[t]{2}{*}{ Sex } & \multirow{2}{*}{$\begin{array}{l}\text { Associated } \\
\text { heart disease }\end{array}$} & \multirow{2}{*}{$\begin{array}{c}\text { Rate in } \\
\text { sinus rhythm }\end{array}$} & \multicolumn{2}{|c|}{$\begin{array}{l}\text { Rate in } \\
\text { auricular tachycardia }\end{array}$} \\
\hline & & & & & Auricular & Ventricular \\
\hline $\begin{array}{l}1 \\
2 \\
3 \\
4\end{array}$ & $\begin{array}{l}65 \\
47 \\
38 \\
41\end{array}$ & $\begin{array}{l}\mathbf{M} \\
\mathbf{F} \\
\mathbf{F} \\
\mathbf{F}\end{array}$ & $\begin{array}{c}\text { Aortic valve sclerosis } \\
\text { Mitral valve disease } \\
\text { Mitral valve disease } \\
\text { None }\end{array}$ & $\begin{array}{l}28-48 \\
35-75 \\
22-43 \\
35-45\end{array}$ & $\begin{array}{c}220-250 \\
180-130 \\
260 \\
270\end{array}$ & $\begin{array}{l}60-120 \\
90-180 \\
50-65 \\
110\end{array}$ \\
\hline
\end{tabular}

the pacemaker in three, and periods of sinus standstill in two (Fig. 1 and 2). The heart rate was found to accelerate steadily in response to effort or emotion, reaching a figure approximately twice that at rest. Abrupt doubling of the rate, as described in sino-auricular block, was not observed.

During the phases of tachycardia (Fig. 3), the ventricular rate varied between 50 and 200 a minute. At the higher rate the rhythm was regular but at the lower rate it was frequently irregular. The electrocardiogram showed auricular tachycardia with an auricular rate varying between 180 and 300 a minute. In the three patients with an auricular rate exceeding 200 a minute there was always auriculo-ventricular block, the ventricular rate being one-half to one-quarter of the auricular rate. (This form of auricular tachycardia is commonly called auricular flutter.) In these three patients the $\mathbf{P}^{\prime}$ wave was inverted in leads II and III (caudal focus (Prinzmetal et al., 1952)) whereas in the patient with an auricular rate below 200 a minute there was an upright $\mathbf{P}^{\prime}$ wave in leads I and II (cephalic focus). 


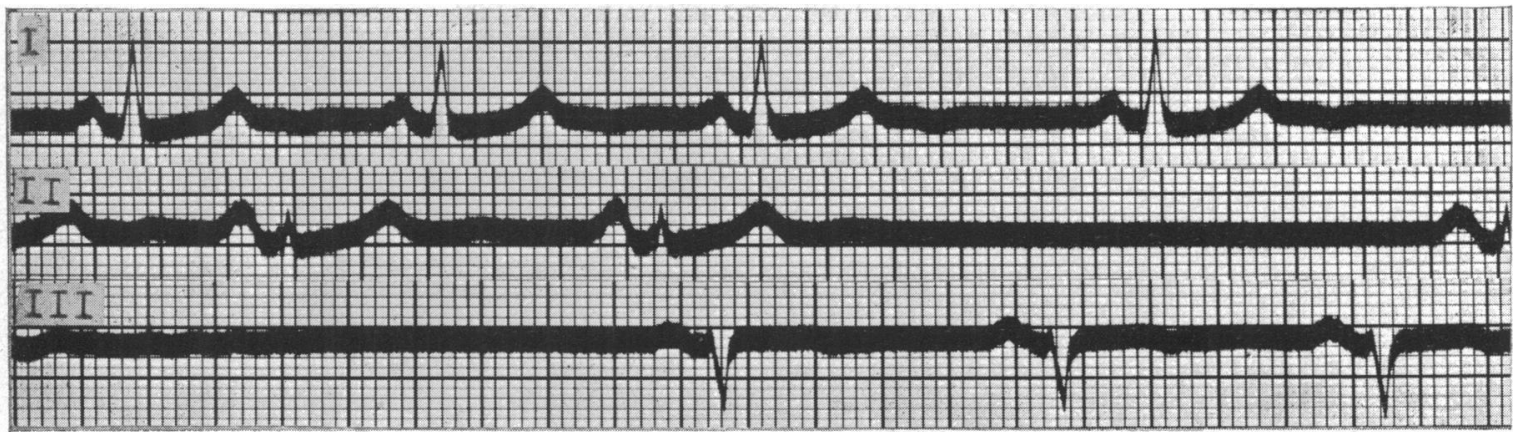

FIG. 1.-Case 4, showing sinus rhythm with periods of sinus standstill. (Time intervals $1 / 5 \mathrm{sec}$.)

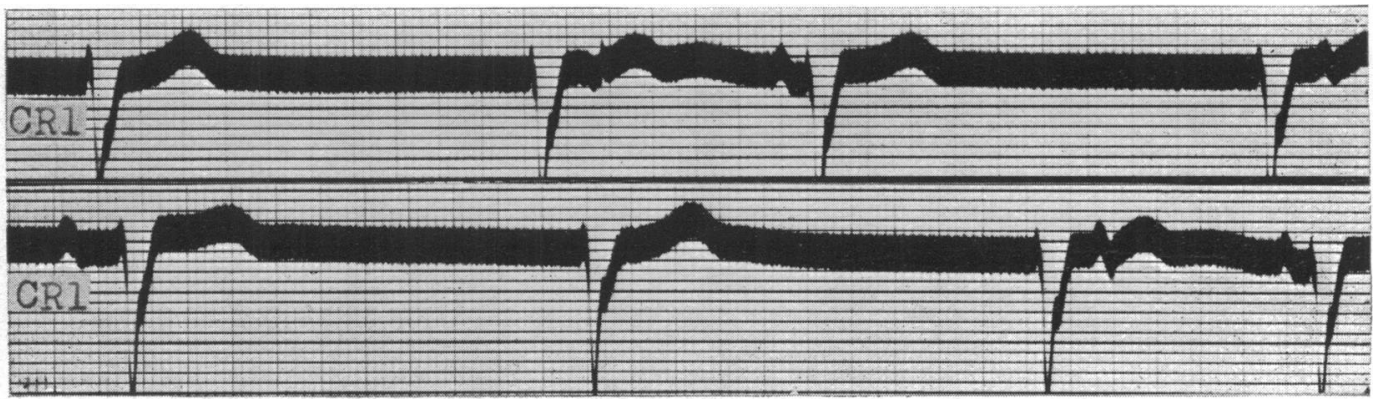

Fig. 2.-Case 3, showing sinus rhythm with wandering pacemaker and A-V nodal escape. (Time intervals $1 / 5$ sec.)

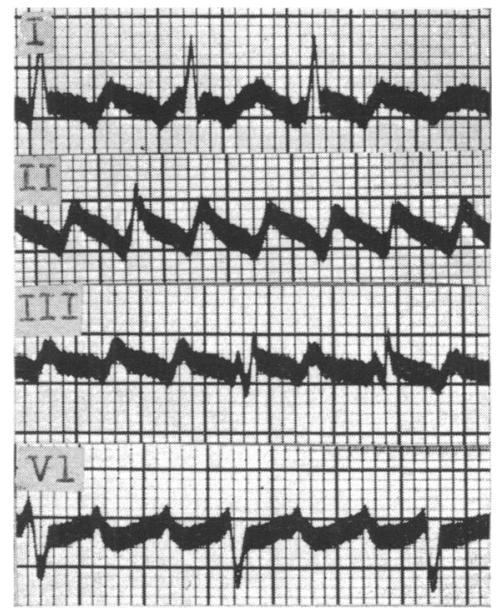

Fig. 3.-Case 4, showing auricular tachycardia (flutter). (Time intervals $1 / 5 \mathrm{sec}$.) 
The paroxysms of tachycardia varied in duration from minutes to months. Each patient had attacks lasting at least one month and two had attacks lasting a whole year. Since the commencement of symptoms each patient spent nearly as long in auricular tachycardia as in sinus rhythm.

\section{SYMPTOMS}

The outstanding symptoms were palpitation and giddiness and, sometimes, unconsciousness. The degree of disability caused by palpitation was directly proportional to the ventricular rate during phases of tachycardia. Thus, in Cases 2 and 4 the disturbance was considerable, in Case 1 it was slight, while in Case 3 the changes in rhythm were unnoticed. Syncope was prominent in all four patients. Transient attacks of giddiness during sinus rhythm were probably due to the exceptionally long diastolic pauses. A minor Stokes-Adams attack of this nature was observed in one patient during auscultation of the heart. Cardiac standstill was accompanied by pallor and followed by flushing of the face. Two patients also suffered from unconsciousness. In one the attacks occurred several times daily for a period; they coincided with the termination of a bout of tachycardia and were probably due to a period of cardiac standstill preceeding the reestablishment of sinus rhythm. In the other patient the mechanism was apparently similar though the history was less definite. One patient developed cerebral infarction, presumably due to embolism.

\section{RESPONSE TO DRUGS}

An intravenous injection of atropine sulphate caused acceleration of the sinus rate in all four patients (Table II). In two, temporary A-V nodal rhythm was observed. Oral administration of atropine sulphate gr. $1 / 100(0.6 \mathrm{mg}$.) thrice daily was tested in each case but in none was any significant effect observed either on the sinus rate or on the incidence of attacks of tachycardia. In two of the patients higher doses could not be tolerated owing to dryness of the mouth. One patient was able to tolerate gr. $1 / 50(1.2 \mathrm{mg}$.) thrice daily with difficulty but even this dose was without effect on the heart rate.

A subcutaneous injection of adrenaline hydrochloride in three patients caused acceleration of the heart in each (Table II). Multiple ventricular extrasystoles occurred in one and transient auricular fibrillation in another.

TABLE II

ResPonse to DRUGS

\begin{tabular}{|c|c|c|c|c|c|c|c|c|c|}
\hline \multirow{3}{*}{ Case } & \multicolumn{4}{|c|}{ Atropine } & \multicolumn{5}{|c|}{ Adrenaline ( 1 in 1000 solution) } \\
\hline & \multicolumn{2}{|c|}{ Dose } & \multicolumn{2}{|c|}{ Heart rate } & \multicolumn{2}{|r|}{ Dose } & \multicolumn{2}{|c|}{ Heart rate } & \multirow{2}{*}{ Side effects } \\
\hline & grains & (mg.) & Before & After & & (mg.) & Before & After & \\
\hline 1 & $\begin{array}{l}1 / 30 \\
1 / 50\end{array}$ & $\begin{array}{l}(2.0) \\
(1.2)\end{array}$ & $\begin{array}{l}32 \\
30\end{array}$ & $\begin{array}{l}48 \\
85\end{array}$ & & & & & \\
\hline $\begin{array}{l}2 \\
3 \\
4\end{array}$ & $\begin{array}{l}1 / 100 \\
1 / 75 \\
1 / 50\end{array}$ & $\begin{array}{l}(0 \cdot 6) \\
(0 \cdot 8) \\
(1 \cdot 2)\end{array}$ & $\begin{array}{l}43 \\
43 \\
33\end{array}$ & $\begin{array}{l}80 \\
84 \\
54\end{array}$ & $\begin{array}{l}0.5 \\
1.0 \\
1.0\end{array}$ & $\begin{array}{l}(0 \cdot 5) \\
(1 \cdot 0) \\
(1 \cdot 0)\end{array}$ & $\begin{array}{l}38 \\
36 \\
43\end{array}$ & $\begin{array}{l}86 \\
85 \\
53\end{array}$ & $\begin{array}{l}\text { Ventricular extrasystoles } \\
\text { Auricular fibrillation }\end{array}$ \\
\hline
\end{tabular}

Ephedrine hydrochloride gr. 1 (0.06 g.) thrice daily was administered for a prolonged period to two patients without significant effect. Other drugs administered orally in an attempt to induce acceleration of the sinus rate included tincture of belladonna 15 minims $(1 \mathrm{ml}$.$) thrice daily,$ benzedrine 5 gr. $(0.3 \mathrm{~g}$.) twice daily, and noradrenaline, a single dose of $20 \mathrm{mg}$.

Large doses of quinidine hydrochloride (gr. 27-30 (1.6-1.8 g.) in one day) whether given prophylactically during sinus rhythm (Case 4) or therapeutically during tachycardia (Cases 2 and 4) led to auricular standstill. In Case 4, the A-V node promptly assumed the function of pacemaker, but in Case 2 the duration of cardiac standstill was so great as to lead to prolonged unconsciousness. 
Procaine amide in a dose of $0.8 \mathrm{~g}$. intravenously (Case 4) or $1.0 \mathrm{~g}$. thrice daily by mouth (Case 2) also produced auricular standstill and in Case 2, cardiac standstill with prolonged unconsciousness resulted.

Two patients were digitalized on several occasions while in tachycardia. In one, the ventricular rate was retarded while the auricular rate remained unaffected. In the other, auricular fibrillation resulted on one occasion and A-V nodal rhythm on another.

Two patients preferred the moderate ventricular rate during auricular tachycardia to the excessive bradycardia of sinus rhythm. In these, therefore, no attempt was made to terminate the ectopic rhythm.

\section{COURSE}

The symptoms were probably uninfluenced by therapy except in Case 2 where the main disability resulted from the high ventricular rate during the paroxysms of tachycardia. In this instance, total thyroidectomy was followed by 18 months' freedom from symptoms.

Three cases were under observation for nearly five years. One developed established auricular fibrillation with relief of symptoms. Another showed no significant change in the clinical picture over a period of almost seven years, though the auricular rate in tachycardia rose from 220 a minute in 1948 to 250 in 1952 . In the third, the auricular rate in tachycardia fell from 200 a minute in 1946 to 140 in 1948 and to 130 in 1952, after thyroidectomy. As a result of this slowing, the symptoms associated with attacks of tachycardia became less severe.

\section{Discussion}

The syndrome of alternating bradycardia and tachycardia is probably related to those rare cases of extreme sinus bradycardia without organic basis described by Trocmé (1922) and Pearson (1950) and also to chronic auricular tachycardia (or flutter) (Lewis, 1937; Schwartz and Levine, 1950). Transient paroxysms of auricular fibrillation or auricular tachycardia have been mentioned in accounts of sino-auricular block by several writers (Levine, 1916; Heimann, 1929; Laake, 1946). These cases bear only a superficial resemblance to the syndrome described here, in that the paroxysms were invariably brief and virtually symptomless; moreover the basic rhythm was classical sino-auricular block.

There is no experimental or clinical evidence that such a syndrome as this can be caused by a structural lesion of the sino-auricular node. Disturbances resembling sino-auricular block have rarely been produced experimentally in animals by direct damage to the sino-auricular node (Barker and Kinsella, 1924; Scherf, 1946) but an injury sufficiently extensive to affect this node at all usually abolishes its control completely, the function of pacemaker being assumed by the A-V node or a portion of the auricular myocardium. Damage to the sino-auricular node in man has occasionally been reported following diphtheria; in the majority of these cases, however, A-V nodal rhythm has resulted (Hume, 1913; Reid, 1930).

The fact that atropine does not raise the sinus rate to the level achieved by a normal subject under similar conditions (Lewis, 1925) suggests that excessive vagal tone is not responsible for the bradycardia in this syndrome. The dose of atropine employed was probably insufficient to paralyse the vagus but the fact that the patients complained of dryness of the mouth while receiving moderate doses shows that they were not resistant to the drug.

In view of the lack of evidence suggesting vagal over-activity as a cause of the bradycardia, and the unlikelihood of an organic lesion of the sino-auricular node, a state of subnormal activity of the node must be assumed. Such a concept would explain several features of the syndrome under discussion. Thus it would account not only for the bradycardia and the paroxysms of auricular tachycardia, but also for the appearance of A-V nodal rhythm following the administration of moderate doses of quinidine or procaine amide and occasionally spontaneously.

Such a hypothesis would also have therapeutic implications. If it were correct, maintenance of the sinus rate at normal levels should not only avoid the symptoms due to bradycardia, but also 
prevent the emergence of the ectopic rhythm. The hypothesis remains unproven, however, for although it was possible to raise the sinus rate significantly by an intravenous injection of atropine sulphate, oral medication was ineffective owing to the side actions of the drug. The ideal drug for this purpose would have atropine-like properties and act selectively on the cardiac branches of the vagus.

Control of the attacks of tachycardia was effected with safety by digitalis. Quinidine and procaine amide in full doses led to auricular standstill and both were responsible for prolonged unconsciousness in one patient.

A means of inducing and maintaining auricular fibrillation in man would be invaluable. One patient in whom this rhythm became established spontaneously lost all symptoms. Unfortunately, it is often impossible to convert auricular tachycardia (flutter) into established fibrillation. Experimental methods of inducing auricular fibrillation in animals (Prinzmetal et al., 1952) are not applicable to man and even if they were, the problem of maintaining the arrhythmia would remain.

In three of the four cases, the symptoms were severe enough to warrant consideration of surgery. One patient has indeed undergone total thyroidectomy with striking temporary relief though the reason for such success is obscure. Interruption of the parasympathetic nerve supply to the heart would seem to be a rational procedure, the practical problems involved are, however, forbidding. Vagotomy cannot be considered because the cardiac branches leave the main trunk above the origin of the recurrent laryngeal nerves. Division of the cardiac nerves themselves would appear to be an operation of considerable technical difficulty particularly on the right side where these nerves pass behind the aorta (Arnulf, 1939; Mitchell, 1953). Denervation of the carotid sinus and aortic arch, an operation that in animals produces an effect on the heart rate almost identical to that of vagotomy (Best and Taylor, 1950) promises to be no easier. Any surgical attack would, in fact, be a pioneer operation of considerable difficulty and, judging from animal experiments (Reed and Layman, 1930), the effect on the heart rate would be unpredictable. Whatever procedure was adopted, it would be prudent to block the vagus before operation with a large dose of atropine to avoid cardiac standstill which might otherwise result from mechanical stimulation of the nerve during dissection.

\section{SUMMARY}

A syndrome characterized by alternation between marked sinus bradycardia and auricular tachycardia (or flutter) is described. Of four patients suffering from such an arrhythmia, two had mitral valve disease, one aortic valve sclerosis, and the fourth no heart lesion.

The most serious symptom was the occurrence of Stokes-Adams attacks. Minor syncopal attacks were frequent during the phases of bradycardia, and palpitation during the bouts of tachycardia.

Although an intravenous injection of atropine caused acceleration of the sinus rate to normal resting levels, no drug was found to have this effect when administered by mouth. Digitalis proved the best remedy to use during paroxysms of tachycardia. Quinidine and procaine amide both caused cardiac standstill.

Of three patients who were observed for five years, the syndrome continued unchanged in two while the third lost all symptoms following the establishment of auricular fibrillation.

The basic fault remains obscure but a concept of subnormal activity of the sino-auricular node would account for most features of the syndrome.

I am indebted to Dr. Bedford, Dr. Brigden, and Dr. Paul Wood for permission to study and report their cases and to Dr. William Evans for much helpful criticism.

Dr. R. Epps was responsible for a number of the observations on Cases 2 and 4. 


\section{CASE Histories}

Case 1. Mr. V.H., aged 65, first attended Dr. Cotton's Out-patient Clinic in 1945 on account of attacks of giddiness, later coming under the care of Dr. Brigden. Examination revealed an aortic systolic murmur. The blood pressure varied between $220 / 100$ and $150 / 75$. The cardiogram showed sinus bradycardia with periods of sinus standstill. During six weeks' observation in hospital the pulse rate varied between 30 and 50 a minute, rarely exceeding the latter figure. Paroxysmal tachycardia was first noted in 1946, the termination of a paroxysm being frequently accompanied by an attack of unconsciousness. For a period during 1948 loss of consciousness occurred several times daily. The cardiogram during auricular tachycardia (flutter) showed an auricular rate of 220 a minute, the $\mathbf{P}^{\prime}$ wave being inverted in leads II and III with a moderate Ta wave. Between 1948 and 1953 there were three prolonged periods of auricular tachycardia lasting 5 months, 11 months, and over 12 months respectively during which the patient was free from symptoms. Between these periods there was frequent alternation between sinus rhythm and auricular tachycardia with repeated attacks of unconsciousness.

Case 2. Mrs. A.M., aged 47, first attended Dr. Bedford's Out-patient Clinic in 1946 on account of paroxysms of tachycardia lasting up to ten minutes with abrupt onset and cessation. They had been occurring for five years but had recently been associated with unconsciousness. Examination showed rheumatic mitral stenosis with moderate cardiac enlargement. The cardiogram showed auricular tachycardia, the auricular rate being 180 a minute; the $\mathbf{P}^{\prime}$ wave was upright in leads I and II with a negligible Ta wave. The ventricular rate was 90 a minute at rest and doubled on effort. The patient was admitted to hospital with the object of restoring sinus rhythm. Digitalis failed to affect the auricular rate though it slowed the ventricular rate. During the following three years she was re-admitted to hospital four times on account of the same symptoms which were not controlled by full maintenance doses of digitalis. An attempt to restore sinus rhythm by means of quinidine was followed by prolonged unconsciousness due to cardiac standstill. Total thyroidectomy was performed in 1949 and this was followed by 18 months' virtual freedom from symptoms. Auricular tachycardia recurred toward the end of 1950 and the paroxysms became gradually more frequent. Since, however, the auricular rate was slower the attacks were less disabling. An attempt to terminate the arrhythmia by means of procaine amide had the same result as in the case of quinidine three years earlier.

Case 3. Mrs. M.K., aged 38, first attended Dr. Bedford's Out-patient Clinic in 1948 complaining that for the past two years she had suffered from attacks of giddiness. Examination showed mitral valve disease with minimal cardiac enlargement. The cardiogram showed sinus bradycardia and left bundle branch block. During six weeks' observation in hospital the heart rate varied between 30 and 60 a minute. During this period there was also one attack of auricular tachycardia (flutter) lasting at least five days in which the cardiogram showed an auricular rate of 260 a minute; the $\mathbf{P}^{\prime}$ wave was inverted in leads II and III with a small Ta wave. For a year the patient remained symptom free despite a pulse rate of 30 a minute until in October, 1949, she sustained a hemiplegia. In 1950 she was again found to be in auricular tachycardia with a ventricular rate of 65 a minute. Two years later she remained well without treatment. Auricular fibrillation had supervened, the ventricular rate being 60 a minute.

Case 4. Miss E.S., aged 41, was admitted to hospital under Dr. Paul Wood in 1951 on account of paroxysms of tachycardia. Three years previously she had been told she had $2: 1$ heart block. On examination, there was no evidence of heart disease. The cardiogram showed auricular tachycardia (flutter), the auricular rate being 300 a minute and the ventricular rate 100 ; the $\mathrm{P}^{\prime}$ wave was inverted in leads II and III with a prominent $\mathrm{Ta}$ wave. Digitalis partially controlled the ventricular rate during tachycardia but did not reduce the frequency of the paroxysms. Quinidine was effective in terminating one attack but it led to auricular standstill. Eventually the attacks subsided spontaneously, the patient being discharged in sinus rhythm with a rate varying between 35 and 40 a minute. The cardiogram showed frequent auricular standstill. A year later the symptoms continued unchanged.

\section{REFERENCES}

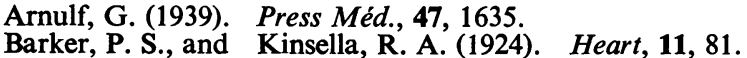

Best, C. H., and Taylor, N. B. (1950). The Physiological Basis of Medical Practice. Ballière, Tindall, and Cox, London, 5th ed., p. 244.

Heimann, H. L. (1929). Bristol Med. Chi. J., 46, 285.

Hume, W. E. (1913). Heart, 5, 25.

Laake, H. (1946). Acta med. Scand., 124, 52. 
Levine, S. A. (1916). Arch. intern. Med., 17, 153.

Lewis, T. (1935). Mechanism and Graphic Registration of the Heart Beat. Shaw and Sons, Ltd., London, 3rd ed., p. 349. (1937). Brit. med. J., 1, 1248.

Mitchell, G. A. G. (1953). Brit. Heart J., 15, 159.

Pearson, R. S. B. (1950). Brit. Heart J., 12, 61.

Prinzmetal, M., Corday, E., Brill, I. C., Obblath, R. W., Kruger, H. E., and Associate Authors (1952). The Auricular Arrhythmias. Springfield, Illinois, U.S.A. (Blackwell Scientific Publications, Oxford).

Reed, C. I., and Layman, J. A. (1930). Amer. J. Physiol., 92, 275.

Reid,W. D. (1930). Amer. Heart J., 5, 524.

Scherf, D. (1946). Proc. Soc. Exper. Biol. Med., 61, 286.

Schwartz, W. B., and Levine, S. A. (1950). Circulation, 1, 936.

Trocmé (1922). Etude des Accidents Syncopaux au Cours des Arrhythmies. Paris, quoted by Wedd, A. M., and Wilson, D. C. (1929-30). Amer. Heart J., 5, 493. 